\title{
Study on Translation Strategies of English Brand Names
}

\author{
Xu Zhang \\ College of Foreign Languages \\ Northeast Electric Power University \\ Jilin, China
}

\author{
Yi Ru Wang \\ College of Foreign Languages \\ Northeast Electric Power University \\ Jilin, China
}

\begin{abstract}
With the continuous development of world economic globalization, international business cooperation and exchanges have become increasingly strengthened. In the increasingly fierce market competition, the brand name has become the core content of enterprise competition. When a local successful brand is going to the overseas market, the most important factor to be considered is the translation of brand name in the target market, in addition to the quality of its products. The target market consumer's attitude towards a new brand or a new product largely depends on its first impression they get from the brand name. Therefore, when translating an English brand name into a Chinese brand name, companies should take a combination of factors into consideration, such as the cultural differences, marketing, psychology and other related disciplines. This essay discusses the issues of English brand names translation from three aspects. The first part analyzes the linguistic features and nonlinguistic features of English brand names. The second part focuses on the four factors that influence the English brand names translation, namely, the target market consumers factors, the original purposes of the English brand names, the purposes of translation and cultural factors. In the third part, it first puts forward the four principles that should be followed in the process of translating English brand names into Chinese, that is, the principles of translation theory, the principles of product attribute, the principles of possessing symbolic and aesthetic meanings, and the principles of marketing. Secondly, by analyzing classic cases, this essay introduces several strategies of English brand names translation, namely transliteration, free translation, creating neologisms and literal translation. At the end of this essay, it summarizes the importance of English brand names in the economic development and the necessities of the study.
\end{abstract}

Keywords-brand names; influence factors; translation strategies

\section{INTRODUCTION}

With the advancement of economic globalization and the activities of international economy and trade all over the world are becoming prosperous increasingly. More and more Chinese enterprises have the opportunities to go abroad to demonstrate the profiles of their enterprises in the international area. However, they are also aware of a problem which cannot be ignored at the same time, and that is, when a brand wants to enter the international market and attract attention of foreign consumers, the most important factor to be considered, besides quality products and services, is having a decent brand name. Bai Guang once proposed that to win the favor of consumer in the increasingly fierce international competition. Brand is critical for commodity producers, and its vitality is far longer and stronger than the goods itself (Bai Guang, 2005). It is no exaggeration to say that the brand is related to whether a product can get consumers' recognition in the target market, and thus directly related to the market efficiency of the products.

There are a variety of brands in the international market. Brand is the sign of goods used by the commodity producers or operators to make their products and services distinguish with the same goods and services of others. It is also an important intellectual property rights related to the survival and the development of enterprises as well as a gold card for the enterprise to foreign markets. Using the brands to promote products and establish a good corporate image has become an important way to tap the international market potential and promote the development of international trade. English brand name translation is to translate the brand from one language into another with the original style and content maintained, rather than simple substitution by the source language into the target language. Wang Hongwei believed that English brand name translation is a comprehensive art, so we need to integrate a wide range of knowledge, such as translation theory, history, culture, aesthetics, psychology, sociology, and to understand the target language audience in the national psychology, values, religious beliefs, aesthetic custom, etc. (Wang Hongwei, 2005). It should not only be closely related to commodity content, but also has a distinctive visual effect in order to leave a deep impression on consumers. Brand names translation from Chinese into English accurately has become a concern that many businesses as well as the translator to consider, therefore, if foreign brands are interested in entering the Chinese market, it is necessary for them to consider how to translate the English brand names into good Chinese brand names.

\section{FEATURES OF ENGLISH BRAND NAMES}

In order to make a better research on the translation strategies of English brand names, the primary task is to fully understand the characteristics of English brand names. The next part of the essay will introduce the characteristics of English brand names from two aspects, namely linguistic features and non-linguistic features. 


\section{A. Linguistic Features}

The linguistic features of English brand names mainly include voice feature, semantic feature and form feature. Understanding and mastering these features will help to improve the accuracy of English brand names translation, and the following is the detailed exposition of these three features.

\section{B. Voice Feature}

In the three decades of reform and opening, thousands of foreign brands have entered the Chinese market. Throughout the Chinese names of English brands, it is not difficult to find that they have a common feature in pronunciation, namely the last word of Chinese brand names often sound loud, clear, and catchy. Foreign brands tend to use alliteration or assonance of continuous word when translated into Chinese, for example, Motorola translated into 摩托罗拉, Tide translated as 汰渍, LUX translated to $力 \pm$, etc. Meanwhile, using a large number of rhetorical languages, such as alliteration, rhyme and assonance translation method, makes the pronunciation of translated names sounds loud, catchy, and lively to meet the aesthetic psychology of Chinese consumers. Coca-Cola is translated as 可口可乐, and choosing this double rhyming words as brand names embodies the pressure of alliteration and the beauty of the music.

\section{Semantic Feature}

English brand names translation should be combined with the characteristics of culture in China. Chinese character is a typical ideogram that is interpreted without real understanding. Affected by such way of thinking, Chinese consumers have already developed a mind-set formula, which is, implying the meaning by seeing the name. So when translated into Chinese, the English brand names should be consistent with the object of cultural connotation and cultural background in order to make consumers accept the translation both in the psychological and emotional pleasantly. In the essence of Chinese culture for many years, home is a core concept. We can often see home related words in many household and daily brands, such as Carrefour-家乐 福, IKEA-宜家. Le is a polyphone in Chinese. When it is made for "yue", it gives a wonderful sense of relax and pleasure. When it appears in Chinese brand name, it delivers a pleasant feeling, such as lays-乐视, Pepsi-Cola-可口可乐.

\section{Form Feature}

The form of a brand name should be concise, easy to pronounce and easy to remember. A statistics found that $70 \%$ of Chinese brand names are only two words, $29 \%$ has three Chinese characters, and only $1 \%$ will be more than three words. Head \& Shoulders, a shampoo brand of Procter \& Gamble, is originally translated into 海伦仙度丝, and lead to over-storage for a long time. Because the translated name is too long, and consumers can't even remember the name of the product let alone the deep meaning of it. Its present name is vivid. "Sea" is reminiscent of cool and comfortable, "fly" embodies the effect of the product, namely using this shampoo can make your hair dry and even have the feeling of flying, and "silk" tells the consumer the purpose of this product.

\section{E. Non-linguistic Features}

Non-linguistic features of the English brand names mainly include association triggering, cultural transferring, consumer tendency and professionalism. This part of essay mainly elaborates that the translated names should cause positive associations of consumers, clearly reflect the attributes of the products, transfer colorful culture and ultimately win the consumer's favor.

1) Association Triggering: A good brand can lead consumers to associate the quality of goods. It is not only the symbol of goods but the commodity advertising. It allows international consumers to produce a pleasant association of related products and enterprises, and then allows them to have a cognition and preference for the brand. For example, the sports brand, Nike, it is the goddess of victory in Greek mythology. If translated into 娜姬, though more in line with the English language and culture, it brings associations with women's gentle, rather than the beauty of sports. 耐克, however, translated into full use of the associative meaning of the word, namely resistance and endurance which is a kind of sports spirit, can show that the product is durable, which can be described as a pun. 克 is reminiscent of winning, which reflects the competitive spirit of sport.

2) Culture Transferring: Brand names can transmit cultural information. Consumers' recognition and associations to the same brand name are different, sometimes even opposite due to the differences in culture, religion, customs, languages, etc. Therefore, just as Lily said, the brand name should fit the cultural values and religious traditions of the target market (Lily, 2001). Gold lion-金利 来, the pronunciation of its translated name is similar with the original's, which gives a person the feeling of good fortune and auspice. It is said that the brand was originally translated into "golden lion". In Cantonese, 狮 is similar with 输, and the business was once bleak. However, the business become very prosperous with posttranslational modification of the brand, and the effect is immediate.

\section{F. Consumer Tendency}

If a brand wants to survive, it must win the consumer groups, understand consumer preferences, and determine how to reflect the essential characteristics of products on the brand name (Bernd H. Schmitt, 2001). Women generally like elegant and mellow brands that are full of romantic atmosphere. So many cosmetics will adopt adjective or flower names with wonderful sense to reflect woman's beautiful appearance and gentle character. Such as Estee Lauder-雅诗兰黛, Clarins-娇韵诗, Vichy-薇姿, etc. They all give a person the sense of pure, fresh and elegant, cater to the consumer psychology of female consumers, attract the attention of consumers, and bring good economic benefits to merchants. While male brands tend to show men's desire for rights as well as their gallantry and bravery, such as the 
famous contact lenses brand Bush \& Lomb. It entered into the Chinese market at the time when Doctor is a symbol of dream, wealth and a better future in China. Its translated name, 博士伦 captures the psychology of consumers, and soon becomes the market leader in contact lenses.

\section{G. Professionalism}

English brand names translation should be combined with product attributes. Items such as toothpaste with the meaning of defending clean, is to keep teeth clean. Crest, for example, the name is the embodiment of the product as an excellent cleaning guard. Another example, such as soap and laundry detergent, both of them have the function of clean. Soap directly contacts with human body skin, which has the function of the aromatic, while laundry detergent does not directly contact with the skin, and consumers expect it to scouring. Like soap brand Dove is translated into 多芬, which is full of affinity; Laundry detergent brand Attack is translated as the 洁霸. The suit brand name Younger means one will be younger when put on it.

\section{INFLUENCE FACTORS OF ENGLISH BRAND NAMES TRANSLATION}

Understanding the features of English brand names is certainly very important, while mastering the influencing factors of English brand names translation is the key to achieve a successful translation. This part mainly expounds the influencing factors of the English brand names translation, namely the target market consumers, the original purposes of English brand names, translation purposes and cultural factors.

\section{A. Target Market Consumers}

Consumers of the target market are one of the key factors that influence the English brand names translation. One once said that Chinese brand names translated from English brand name and the potential desires for purchasing of the consumers in the target market are closely linked (Sheng Zhiyang, 2003). Appropriate translation can satisfy the requirement of potential customers in the target market, stimulate their desire to purchase, and finally produce purchase behavior. In general, westerners tend to accept new things, and the Chinese tend to accept the traditional form. English brand names can be translated into traditional form or westernized form. The choice depends on the enterprise's positioning to the consumer groups in the target market. If the product positioning in the target market are somewhat younger, companies can consider a more westernized translation; if the product is positioned to aging, it would better to use the traditional translation. Converse is a famous brand of canvas shoes in the United States. The first pair of All Star canvas shoes, born in 1917, is favored by the U.S. professional basketball stars and deeply loved and sought after by young people after entering into the Chinese market in 1992. Converse means retrograde and reverse which represents the rebellious spirit of western people. Translated as 匡威 in the Chinese market, it upholds the original connotation and spirit of the brand, meanwhile, it locks consumer groups for young people in the Chinese market, so that the brand "converse" can make it possible to do a good job in the Chinese market.

\section{B. Original Purposes of the English Brand Names}

When people create an original brand name, they will take the characteristics of their products into account as well as various aspects related to their products. The brand should reflect the essential attribute of the product, and allow consumers to make a general judgment on product category as quickly as possible. Words or phrases used for brand names have some common language features: loud and clear, concise and easy to remember. In the process of translation, the brand names should also have the same characteristics as much as possible. For example, in terms of Kodak, it is a brand name without any sense. However, we can work on the pronunciation of the Chinese character 达 because of its loud and clear pronunciation. Although "Kodak" is not an original fixed vocabulary in the Chinese language, it has the effect of loud pronunciation. The most important thing is that it has a complete meaning of vocabulary and similar beauty with the original Kodak at this point.

\section{Purposes of Translation}

Broadly speaking, the purposes of brand name translation are improving the sales of the products in the target market; narrowly speaking, its purposes aim at recreating the original brand names in the target language environment or blending the original brand into the local culture (Yu Fulin, 2003). We are all familiar with the English brand Coca-Cola and Pepsi. It is obvious that both of them take Chinese local culture into account when they enter into the Chinese market for their rich reflection of Chinese cultural characteristics. In contrast, Givenchy and Dior such brand names pay more attention to the cultural characteristics of the product itself when translated into Chinese. Givenchy highly praises elegant, fashion, and concise. Dior has been synonymous with gorgeous and elegant. Their Chinese name 纪梵希 and 迪奥 can reflect the theme of the product, namely elegant and fashion, but there are no more Chinese characteristics inside.

\section{Cultural Factors}

Cultural factor is one of the key factors affecting English brand name translation. Cultural factor is also a bi-cultural factor to be considerate at the same time. In other words, we should not only consider its own cultural factors included in the original English brand name, but also cultural factors of the target market. Toyota models PRADO had been translated into 霸道, and the essence that "PRADO" want to promote is: Experience the uninhibited freedom of driving and fully show the uninhibited power of urban life. However, its translation not only failed to reflect the original connotation of the brand, but made it difficult for the Chinese people to accept emotionally. So the enterprise had no choice but to change its brand name for 普拉多 when it entered into the Chinese market. Opium is a kind of perfume brand, translated as 鸦片 when entered into the Chinese market in 1982. Obviously, this is not in accordance with Chinese culture. First of all, the opium is contraband in China; second, most of Chinese consumers will think of the history of the opium war when refer to opium, and then reject the brand psychologically. 


\section{PRINCIPLES AND STRATEGIES OF TRANSLATION}

The translation of English brand names should follow certain translation principles and adopt some translation strategies. This part of essay mainly introduces four kinds of translation principles, namely following the principle of translation theory, embodying the product attribute theory, possessing symbolic meaning and aesthetic meaning, and following the principles of marketing. It also expounds four translation strategies of the English brand names, namely transliteration, free translation, creating neologisms, and literal translation.

\section{A. Principles of Translation}

Many principles should be followed in the process of English brand names translation, and there are four main principles in this part of the essay.

\section{B. The Principle of Translation Theory}

Translation of English brand names should be based on certain translation theory and follow certain translation principles. In Nida's dynamic equivalence translation theory, he proposes that the concern of the translator is not the corresponding relation between source language information and the target language, but a dynamic relationship. The relationship between the target language receiver and the target language information should be basically the same with the relationship between the source language receiver and the original information (Nida, 1993). In addition, according to Nida's equivalence theory, English brand names translation must have two conditions: the form of translated name itself should have the form of brand name; the translated name must be able to generate the same or similar function with the original brand name (Nida, 1984). That is to say, the translation of brand names should be easy to read, nice, and good-looking, and only in this way, the sound, form, and meaning can be combined perfectly.

1) Embodying the Product Attribute Theory: Dedicated as a specific commodity name, brand plays an important role in product promotion (Huang Jing, 2014). If a brand name reflects certain product attributes, consumers can cognitive the product information quickly, such as the type, function, properties, or target consumers. Benz, translated as 奔驰, easily enables Chinese people to associate it with fast running. They think this car must come and go like the wind, and the brand achieves good publicity effect so as to gain more sales and better economic benefit. McDonald's, Kodak, and Audi reveal the foreign brand information. McCormick, 味可美 directly shows good favor of the product to the potential customers. Rejoice, translated as 飘柔rather than 欢乐or欢欣, shows the excellent performance of the product, and win the female consumers at the same time.

2) Possessing Symbolic Meaning and Aesthetic Meaning: In addition to having a certain value of information, a successful brand also has a rich symbolic meaning which gives people the enjoyment of beauty, and thus it plays a role in promoting sales. The Crown car, for example, the brand itself is a symbol of elegant, which like a Crown with royal style. Another example is a glasses factory brand OIC, the three letters together link the shape of a pair of glasses, with its pronunciation closing to "Oh, I see". It unites image and meaning, which gives people the enjoyment of pleasure.

\section{Following the Principles of Marketing}

Brand is both a part of the goods itself, and the foundation of the commodity into the market. The ultimate goal is to attract the attention of consumers and stimulate their desire to purchase and promote product sales. Therefore, English brand names translation should also consider the principles of marketing. That is to say, in order to enter Chinese market, foreign products should adopt corresponding countermeasures according to the psychological characteristics of Chinese consumers, and make fully consideration for the type of the brand name. The translated brand name should cater to the specific consumer group, and thereby expand the market influence. Youngsters are in pursuit of modern fashion, so "McDonald's", "KFC" whose brands are full of foreign flavors, more conforms to the mind of the youth. In addition, although Deerway is a local brand, it is also full of exotic atmosphere. The high fitness degree of its name and its product attributes makes it a classic case of product naming.

1) Strategies of Translation: In addition to following certain principles in the process of translation, making use of certain translation strategies is also of importance, and there are several typical strategies for translating.

2) Transliteration: Transliteration is a kind of translation form based on the original language pronunciation. It is a more direct translation method applicable to products that have made certain visibility, such as Nokia, Motorola, Chanel, Gucci, etc. By using transliteration, this kind of product will be quickly recognized by the Chinese consumers for its unique foreignness without causing the conflict between Chinese traditional culture and foreign culture. The pronunciation become loud and clear after being transliterated, which in turn, the brand name will be easy to remember and deeply rooted in the hearts of the people. Transliteration is divided into pure transliteration, homophonic translation and omission transliteration.

Pure transliteration means using a similar pronunciation of Chinese characters matches the translation whose basis on the pronunciation of the English word by word. It is mainly suitable for proper nouns, such as name brands and place name brands.

Homophonic translation is based on sound teases. Generally, it changes individual words on the basis of pure transliteration. For example, in order to commemorate the airlines founder William Edward Boeing, people determined to use his name 博音 as the brand name. However, the brand translator switches it with its harmony 波音 that can make people have endless reverie on this kind of supersonic aircraft.

Omission transliteration is based on the aesthetic habits of Chinese people. Two-syllable and three-syllable brand names can be more unforgettable. The British car brand 
Rolls Royce use 劳斯莱斯 instead of 罗尔斯-罗伊斯, it adopts a more straightforward translation to promote sales.

\section{Free Translation}

Free translation is determined according to the content meaning of original language. It is based on the meaning of the original brand, namely translating English into Chinese with their meanings similar or the same with each other. Free translation can well reflect the original intention or hope of the original brand establishment. When the meaning of the English brand name is corresponding with Chinese, enterprises can translate directly according to the meaning of English brand name, such as the Crown, Microsoft, and Volkswagen. The volks is the meaning of the masses, and wagen means cars. When the Chinese meaning of the brand name do not correspond with its English brand name, we can translate by linking the product function to the product category. Safeguard means protection in Chinese; obviously this can't be a brand name. The translator determined 舒肤佳 as its brand name according to its product category and product properties, which makes the consumer feel that their skin is protected.

Some brands may not be able to express the connotation of brand completely if translated according to the literal meaning. At this time, we should choose the best and most representative meaning of the brand. Such as the cigarette brand Good Company, it can be translated as a good friend, a good partner, a good company, and so on. At last, it chose the best one for its brand name.

\section{E. Creating Neologisms}

Creating a new lexical is another translation method. It is actually an innovation that highlights the characteristics of their products in their own country's language. A typical example is the Sprite. The meaning of the word is little devil, goblins. Westerners think that it is an interesting name, and like to buy. However, Chinese consumers don't agree with it. Translated as 雪碧 which added a kind of associative meaning on the basis of harmonics makes the consumers feel cool and quench their thirst. Another example, such as IKEA, a furniture brand, very few people know the meaning of it even in Sweden. However, the smart translator gives it the beautiful meaning 宜家.

\section{F. Literal Translation}

Literal translation is the most commonly methods of translation used in the import and export commodities. Fair Lady-贵夫人 (bedding brand), American Standard-美标 (sanitary ware brand), Crown- 皇冠 (car brand), Good Companion-良友 (cigarette brand), Apple-苹果 (computer brand) are all popular brands. The distinctive feature of these brands is that they all imply their meanings. In this way, it is easy for consumers to make association, and they could not help but generating good wishes to the commodities, which benefit the promotion of the products. Some brands are derived from the myths and legends, and enterprises must reflect the cultural implication as much as possible in the process of translation. A lot of domestic brands have a great reputation in the domestic market. However, they get the brands competitiveness reduced when they enter the foreign markets. Because they ignore that when in Rome, do as the Romans do in the process of translation.

\section{CONCLUSION}

Brand is a kind of special language symbol, an enrichment of the commodity remarkable feature, an important part of commodity culture, and a powerful weapon for enterprises to participate in international competition. It is not only the performance of product image and quality, but also represents a corporate image. Therefore, the translation of brand manes is of great practical significance. The enterprises should make accurate translation of the original product without losing the artistry and commercialization of the original brand names. It should also express the connotation that the original brand name wants to do, and arouse potential customers' purchasing motivation to achieve a wide range of publicity and promotion of product sales purposes. Moreover, the translation of brand names has rich theoretical significance at the same time. The translation of English brand names can not only broaden the space of linguistic research, enriches the connotation of linguistics, but also promote the organic combination of linguistic theory research and practical application.

To do a good job in English brand names translation into Chinese requires the translator to understand the cultural background of the target market, to know the cultural differences between Chinese and foreign languages, and to follow the social cultural habits and the public aesthetic psychology. Only being good at figuring out consumer psychology, respecting the customs of ethnic minorities, properly using the brand name translation methods and techniques, can the enterprises enable the translated brand to dominate in the commercial war, to lead consumption, and to promote consumption. Good Chinese brand names translated from English brand names reflect the perfect combination of translation technology and aesthetic art, which adds infinite charm to the product packaging, provides impetus for enterprises to enter the international market, and promotes the process of economic globalization.

\section{REFERENCES}

[1] Eugene A. Nida. Language, Culture and Translating [M]. Shanghai: Foreign Language Education Press, 1993.

[2] Hornby, A. S. Oxford Advanced Learner's English-Chinese Dictionary [Z]. Beijing: The Commercial Press, 1948.

[3] Jin Di and Eugene A. Nida. On Translation [M]. Beijing: Translation \& Publishing Corporation, 1984.

[4] Lily C. Dong and Marilyn M. Helms. Brand Name Translation Model: A Case Analysis of US Brands in China [J]. Brand Management, (2): 99-115, 2001.

[5] Shi Zhang and Bernd H. Schmitt. Creating Local Brands in Multilingual International Markets [J]. Journal of Marketing Research, (3): 38-44, 2001.

[6] Huinan Bao. Cultural Context and Language Translation [M]. Beijing: China Translation Corporation, 2001.

[7] Guang Bai. The Story of Brand Creativity [M]. China: China Economy Press, 2005.

[8] Jing Huang. Chinese Translation of English Brand Names and Its Translation Principles [D]. Shanghai: Shanghai Normal University, 2014. 
[9] Kaibao Hu, Zaiquan Chen. The Aesthetic Features of Commodity Names and the Translation of English Commodity Names [J]. China Translation, (5): 51-53, 2000.

[10] Haiyan Ma. Cultural Differences and Translation in Brands [J]. Journal of Zhejiang Wanli University, (1): 49-51, 2006.

[11] Yangzhi Shen. National Cultural Factors in Brand Translation [J]. China Business Update, (8): 34-42, 2003.

[12] Hongwei Wang. On the Translation of Chinese Brand Names from an Intercultural Perspective [D]. Dalian: Dongbei University of Finance and Economics, 2005.

[13] Shanwen Xu. Aesthetic Features of Chinese Translation of Cosmetic Brands [J]. Science and Technology Information, (2): 127-132, 2007.

[14] Feng Wu. Pragmatic Translation: Theory\&Practice [M]. Hangzhou: Zhejiang University Press, 2008.

[15] Fulin Yu. Business English Translation [M]. Beijing: China Commerce and Trade Press, 2003. 